\title{
Apoplastic pH Signaling in Barley Leaves Attacked by the Powdery Mildew Fungus Blumeria graminis f. sp. hordei
}

\author{
Hubert H. Felle, ${ }^{1}$ Almut Herrmann, ${ }^{1}$ Stefan Hanstein, ${ }^{1}$ Ralph Hückelhoven, ${ }^{2}$ and Karl-Heinz Kogel ${ }^{2}$ \\ ${ }^{1}$ Botanisches Institut I, Justus-Liebig-Universität, Senckenbergstraße 17, D-35390 Gießen, Germany; ${ }^{2}$ Interdisziplinäres \\ Forschungszentrum für Umweltsicherung, Institut für Phytopathologie und Angewandte Zoologie, Justus-Liebig- \\ Universität, Heinrich-Buff-Ring 26-32, D-35392 Gießen, Germany
}

Submitted 21 July 2003. Accepted 23 September 2003.

To investigate apoplastic responses of barley (Hordeum vulgare L.) to the barley powdery mildew fungus Blumeria graminis f. sp. hordei, noninvasive microprobe techniques were employed. $\mathrm{H}^{+}$- and $\mathrm{Ca}^{2+}$-selective microprobes were inserted into open stomata of barley leaves inoculated with Blumeria graminis f. sp. hordei race A6 conidia. Resistance gene-mediated responses of barley genotype Ingrid (susceptible parent line) and the near-isogenic resistant Ingrid backcross lines (I-mlo5, I-Mla12, and I-Mlg) were continuously monitored from $20 \mathrm{~min}$ to 4 days after inoculation. The main events were categorized as short-term responses around $2 \mathrm{~h}$ after inoculation (hai), intermediate responses around 8 and 12 hai, and long-term responses starting between 21 and 24 hai. Short-term responses were rapid transient decreases of apoplastic $\mathrm{H}^{+}$- and $\mathrm{Ca}^{2+}$ activities that lasted minutes only. Kinetics were similar for all genotypes tested, and thus, these short-term responses were attributed as nonspecific first encounters of fungal surface material with the host plasma membrane. This is supported by the observation that a microinjected chitin oligomer $(\text { GlcNAc })_{8}$ yielded similar apoplastic alkalinization. Intermediate responses are trains of $\mathrm{H}^{+}$(increase) spikes that, being different in susceptible Ingrid and penetrationresistant I-mlo5 (or I-Mlg), were interpreted as accompanying specific events of papillae formation. Long-term events were massive slow and long-lasting alkalinizations up to two $\mathrm{pH}$ units above control. Since these latter changes were only observed with near-isogenic hypersensitive reaction (HR)-mounting genotypes I-Mla12 and I-Mlg but not with I-mlo5 or, to a smaller extent, with susceptible Ingrid, both lacking significant rates of $H R$, they were rated as cell death specific. It is concluded that apoplastic $\mathrm{pH}$ changes are important indicators of host-pathogen interactions that correlate with both the different stages of fungal development and the different types of host defense response.

Signaling between phytopathogenic fungi and their hosts starts after a first encounter, i.e., when fungal conidia come into physical contact with the plant surface. If conditions are favorable, conidia start to germinate, which, in the case of powdery mildew fungus Blumeria graminis f. sp. hordei, commences with a noninvasive primary germ tube (PGT), fol-

Corresponding author: K.-H. Kogel; Telephone: +49 (0)641 9937491; Fax: +49 (0)641 9937499; E-mail: Karl-Heinz.Kogel@agrar.uni-giessen.de lowed by the formation of an appressorial germ tube and an appressorium and, in case of a successful penetration, with formation of a haustorium inside the epidermal host cell. It may be a matter of debate if or to what extent the host experiences in the first seconds or minutes the encounter of its surface with the conidia. However, after penetration of the cuticle, a first direct contact with the host's plasma membrane takes place, to which the host responds accordingly. Since Blumeria graminis does not cross the membrane barrier of host cells, interactions between fungus and host take place mainly in the apoplast, and changes of the ionic milieu are to be expected. Within the thin aqueous apoplastic layer, $\mathrm{pH}$ is a most important parameter, because it optimizes both membrane transport and enzyme activities. In order to test and analyze this variable parameter after inoculation of barley leaves with powdery mildew conidia, we inserted ion-selective microprobes into open stomata in the immediate neighborhood of an interaction site. By monitoring apoplastic $\mathrm{pH}$ continuously for several days, this entirely noninvasive approach guaranteed that the host-pathogen interactions were picked up undisturbed in the way they occur in the intact plant.

Resistance $(R)$ genes mlo5 (recessive), Mla12, and Mlg govern fungal arrest at distinct stages of the interaction of barley with Blumeria graminis f. sp. hordei A6: mlo early (12 to $24 \mathrm{~h}$ after inoculation [hai]) at the penetration stage within cell wall appositions (effective papillae), leaving the attacked cell alive; Mlg (by 12 to 24 hai) within papillae of cells that subsequently undergo a hypersensitive cell death (HR) (20 to 30 hai); and Mla12 after successful fungal penetration by a subsequent delayed HR (24 to 48 hai) (Hückelhoven et al. 1999; Jørgensen 1994). Since we assumed that such specific defense reactions influence the apoplastic ionic milieu in a characteristic manner, we attempted to analyze the quality of defense responses of these near-isogenic barley genotypes towards infection with Blumeria graminis f. sp. hordei A6 by measuring ion activities. We demonstrate that the development of apoplastic $\mathrm{pH}$ is closely associated both with different stages of host-pathogen interaction and with the quality of cellular defense responses mediated by the various $R$ genes.

\section{RESULTS}

Short term responses.

After inoculation with the conidia of Blumeria graminis $\mathrm{f}$. sp. hordei A6, the first leaf was mounted in a cuvette, as described below, and the electrodes were brought into position 
within stomata as close as possible to the conidia. The preferred position was where one or more conidia lodged between two open stomata, into which the electrodes (ion-selective and voltage reference) were inserted until contact with the apoplastic fluid was obtained. This closed the electrical circuit through the leaf apoplast with the bath reference (Hanstein and Felle 1999; Felle et al. 2000a). The positioning procedure took approximately $20 \mathrm{~min}$, after which the recordings were started. By 1.5 hai, the mean apoplastic $\mathrm{pH}$ was $4.89 \pm 0.23$ standard error (SE) $(n=11)$ for the susceptible parent Ingrid, $4.8 \pm 0.2$ $\mathrm{SE}(n=10)$ for I-mlo5, $5.0 \pm 0.12 \mathrm{SE}(n=14)$ for I-Mlg, and $4.9 \pm 0.1 \mathrm{SE}(n=5)$ for I-Mla12. Figure 1 shows that, for susceptible Ingrid by about 2 hai, the apoplastic $\mathrm{pH}$ began to rise rapidly from 4.9 to reach a peak at 5.4 after 2 min (mean $\mathrm{pH}$ change $0.54 \pm 0.07 \mathrm{SE} ; n=5$ ). At the same time, the apoplastic voltage became transiently more negative by roughly $25 \mathrm{mV}$ (mean voltage change $23.6 \pm 0.42 \mathrm{SE} ; n=3$ ), which would be equivalent to a plasma membrane depolarization of cells nearby. The similarity of the two kinetics obtained from different barley leaves demonstrates the reproducibility of the measurements. In Figure 2A the $\mathrm{pH}$ effects of resistant genotypes IMla12, I-Mlg, and I-mlo5 are shown, together with a $\mathrm{Ca}^{2+}$ response (I-Mla12). Clearly, the kinetics from different measurements or genotypes are comparable in the extent of absolute $\mathrm{pH}$ change as well as in duration, indicating that this response is $R$ gene independent and, thus, nonspecific. The observation that $\mathrm{Ca}^{2+}$ and $\mathrm{pH}$ responses are rather similar in timing points to a close relation of these events.

Since we suspected that responses were initiated by the first encounter of pathogen-associated molecular patterns with the host plasma membrane following penetration of the cuticle, we tested the effect elicitor-active chitin fragments would have on the leaf apoplast. In order to perform this, the chitin oligomer (GlcNAc) $_{8}$ was injected directly into the first leaf apoplast through a stoma nearby. As Figure $2 \mathrm{~B}$ shows, injection of a chitin fragment was responded to with an increase in apoplastic $\mathrm{pH}$, the shape and extent of which was rather similar to the kinetics shown in Figures 1 and 2A. Notably, injection of $(\text { GlcNAc })_{8}$ resulted in a $R$ gene-independent accumulation of the pathogenesis-related (PR) proteins chitinase and $\beta-1,3$-glucanase in Ingrid and I-Mla12, as shown by immunoblot analysis (data not shown).

\section{Intermediate and long-term responses.}

As shown in Figures 3A and 4A, trains of four to five $\mathrm{pH}$ spikes in the susceptible line Ingrid occurred around 8 hai and, after a $2 \mathrm{~h}$ pause, resumed again around 12 hai. These spikes were smaller than the single events around 2 hai but lasted longer and are temporally linked to the formation of papillae or the formation of the fungal appressorium. As shown in Figure $3 \mathrm{~B}$, around the same time and in similar intervals, $\mathrm{Ca}^{2+}$ spikes occurred. The $\mathrm{pH}$ spikes went in the acidic direction (increase in $\mathrm{H}^{+}$activity), whereas the $\mathrm{Ca}^{2+}$ spikes were transient apoplastic $\mathrm{Ca}^{2+}$ decreases, presumably meaning $\mathrm{Ca}^{2+}$ influx into the symplast. This differs from the short-term events in which both $\mathrm{Ca}^{2+}$ and $\mathrm{H}^{+}$activities decreased.

Intermediate $\mathrm{pH}$ spikes were also observed with I-mlo5 and I-Mlg (Fig. 4C and D), which much more frequently mount papillae at sites of attempted infections as an effective defense response (Hückelhoven et al. 1999). Accordingly, in comparison with susceptible Ingrid, the events were fewer but longer lasting and more substantial, which was especially evident for the 12 to 16 hai period when the fungus attempts to penetrate. This observation clearly reflects the action of the different $R$ genes. Clear grouping of the spikes did not always occur, and arbitrary single spiking in the acidic direction was observed throughout the measurements. A quantitative treatment of these spikes is difficult but, on the average, the $\mathrm{pH}$ changes were $0.32 \pm 0.04 \mathrm{SE}(n=3)$ for susceptible Ingrid, $0.41 \pm 0.11 \mathrm{SE}(n$ $=3$ ) for I-Mlg, $0.65 \pm 0.27 \mathrm{SE}(n=5)$ for I-mlo5, and $0.46 \pm$ $0.08 \mathrm{SE}(n=3)$ for I-Mlal2.

Long-term experiments covered a time range of several days. Representative protocols for the genotypes Ingrid, IMla12, I-mlo5, and I-Mlg are shown in Figure 4. To provide a better insight in the entire $\mathrm{pH}$ development after inoculation, intermediate and long-term kinetics are given together. The most massive $\mathrm{pH}$ changes were observed with I-Mla12 and I$M l g$, which mount an HR in about 65 (I-Mla12 by 24 to 48 hai) and $80 \%$ (I-Mlg by 20 to 30 hai) of infection sites, respectively (Hückelhoven et al. 1999). Between 21 to 24 hai, apoplastic $\mathrm{pH}$ started to increase and, in the cases of I-Mlal2 and I-Mlg, reached $6.85 \pm 0.22 \mathrm{SE}(n=3)$ and $6.9 \pm 0.1 \mathrm{SE}(n=3)$, respectively, remaining relatively constant for about 1 day (IMla12). For I-Mlg the increase and recovery of the $\mathrm{pH}$ started earlier, consistent with the earlier onset of HR. Apart from occasional intermediate peaks in the acidic direction, the $\mathrm{pH}$ dropped spontaneously to a value of 5.0 to 5.3, barely above the basic apoplastic $\mathrm{pH}$ of the undisturbed leaf. Light-off and light-on control tests (not shown) show that, after 3 days, the photosynthetic $\mathrm{pH}$ response is still in operation, i.e., the leaf's responses were still in order, although locally around the infection sites cell death (HR) might have taken its toll. Significantly, the long-term $\mathrm{pH}$ increase with susceptible Ingrid, which mounts a HR at about $10 \%$ of interaction sites, is considerably smaller and just reaches $5.9 \pm 0.16(n=3)$. Interestingly, I-mlo5, which does not show HR, yielded an entirely different long-term response, thus making the long term events $R$ gene dependent and specific with respect to the quantity and quality of defense responses; at 21 to 24 hai, when the apoplastic $\mathrm{pH}$ of Ingrid, I-Mlg, and I-Mla12 started to increase significantly, no response occurred with I-mlo5. Nevertheless, apoplastic $\mathrm{pH}$ did (continuously) increase but already during the

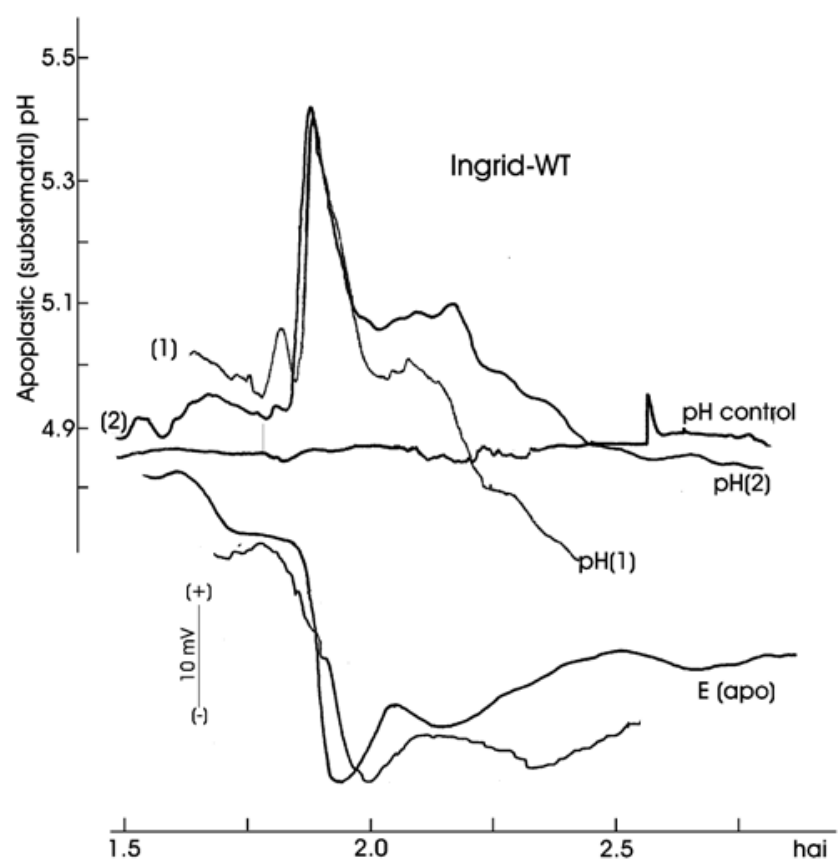

Fig. 1. Short-term $\mathrm{pH}$ - and voltage responses $\left(\mathrm{E}_{\mathrm{apo}}\right)$ measured within the apoplast (apo) of barley leaves (susceptible parent Ingrid) inoculated with Blumeria graminis f. sp. hordei A6 conidia. Kinetics from two different leaves $(1,2) . \mathrm{pH}$ and $\mathrm{E}_{\text {apo }}$ were recorded simultaneously on the same leaf. Representative of five $(\mathrm{pH})$ and three $\left(\mathrm{E}_{\mathrm{apo}}\right)$ equivalent recordings, each. ' $\mathrm{pH}$ control' represents a recording without infection. hai $=$ hours after inoculation . 
acidic intermediate peaks, reaching $\mathrm{pH} 5.6 \pm 0.21 \mathrm{SE}(n=4)$, similar to that observed for susceptible Ingrid.

\section{DISCUSSION}

\section{Microprobe technique.}

Monitoring apoplastic ion activities directly by placing ionselective microprobes in the substomatal cavities is a recognized noninvasive technique that has been applied successfully by us for a variety of scientific problems (Felle and Hanstein 2002; Felle et al. 2000b; Hanstein and Felle 1999). As the microprobes do not change the ionic milieu of the apoplastic fluid or disturb the leaf in any way, it is the technique of choice when interactions of two organisms are to be investigated in vivo during a time interval that extends over several days. Since the recordings are continuous, no information is lost through handling throughout the entire experiment.

\section{The early events are local effects.}

The 2-hai event was not observed in all preparations, although the intermediate and long-term effects occurred and the conidia near the measuring site had germinated (data not shown). It is suggested that the 2-hai effect is a highly local event that does not spread or reach far from the attacked site, i.e., not further than two or three cells. Two-electrode kinetics (Fig. 4C) (Felle et al. 2000a) prove that this observation is by no means a measuring problem arising from the distance of the two electrodes either from each other or from the infection site.

\section{pH and $\mathrm{Ca}^{2+}$ interactions.}

The apoplast is the space where most early signals are sent to and received. As in the cytoplasm, $\mathrm{Ca}^{2+}$ may be a signal or a messenger in the apoplast but, in any case, serves as temporary reservoir to quickly increase cytosolic $\mathrm{Ca}^{2+}$ after activation of $\mathrm{Ca}^{2+}$-conducting channels. Examples thereof may be the sharp $\mathrm{Ca}^{2+}$ spike around 2 hai or the trains of spikes around 8 and 12 hai, respectively. In both cases, $\mathrm{Ca}^{2+}$ leaves the apoplastic space and presumably leads to increases in cytosolic free $\mathrm{Ca}^{2+}$ within the cells nearby. According to the changes in apoplastic
$\mathrm{Ca}^{2+}$ activity at 2 hai, such an increase in cytosolic $\mathrm{Ca}^{2+}$ must be massive but relatively short. From tests with elicitors (Blume et al. 2000; Mithöfer et al. 1999; Felle et al. 2000a) and Nod factors (Felle et al. 1998), it is known that activation of $\mathrm{Ca}^{2+}$ influx is the earliest measurable event leading to activation of anion channels or deactivation of the plasma membrane $\mathrm{H}^{+}$ATPase, which in both cases leads to depolarization, as also demonstrated here (Fig. 1). Apart from depolarizing inorganic anions, organic anions leave the cells also and, by taking $\mathrm{H}^{+}$out of their equilibrium, alkalinize the external space, which may provoke the alkalinization observed (Figs. 1 and 2). External alkalinization may also be promoted by a decrease in $\mathrm{H}^{+}$pump activity. This sequence of events apparently is a general principle of defense and a typical response to elicitor molecules like chitin fragments, by which the system gets alarmed.

The intermediate $\mathrm{Ca}^{2+}$ changes are less substantial but longer lasting than the singular 2-hai event and, thus, probably are not a signal per se but a result of underlying processes. We know that within this time interval cell wall appositions (papillae) form that, at some stage, may require the presence of elevated cytosolic $\mathrm{Ca}^{2+}$. This is supported by the finding that presence of external $\mathrm{Ca}^{2+}$ is required for effective papilla formation in mlo barley (Bayles and Aist 1987). In contrast, Kim and associates (2002) recently found that the functional MLO protein interacts with calmodulin, which is required for full MLO function in conferring susceptibility to powdery mildew fungus. Therefore, one may speculate whether the $\mathrm{Ca}^{2+}$ influx, detected here indirectly by apoplastic decrease of $\mathrm{Ca}^{2+}$, is involved in compatibility mechanisms.

The $\mathrm{pH}$ spikes obviously go in the acidifying direction, indicating quite a different response. Apoplastic acidification could mean activation of the $\mathrm{H}^{+}$pump, although $\mathrm{Ca}^{2+}$ and $\mathrm{H}^{+}$antiporter activity would also be a faint possibility. Since, to date, we have no evidence that $\mathrm{Ca}^{2+}$ and $\mathrm{H}^{+}$move in different directions at the same time, the latter would be mere speculation, however. Activation of the $\mathrm{H}^{+}$pump would in any case be indicative of increased cellular activity at the infection site. The reason why such activation manifests itself in trains of $\mathrm{pH}$
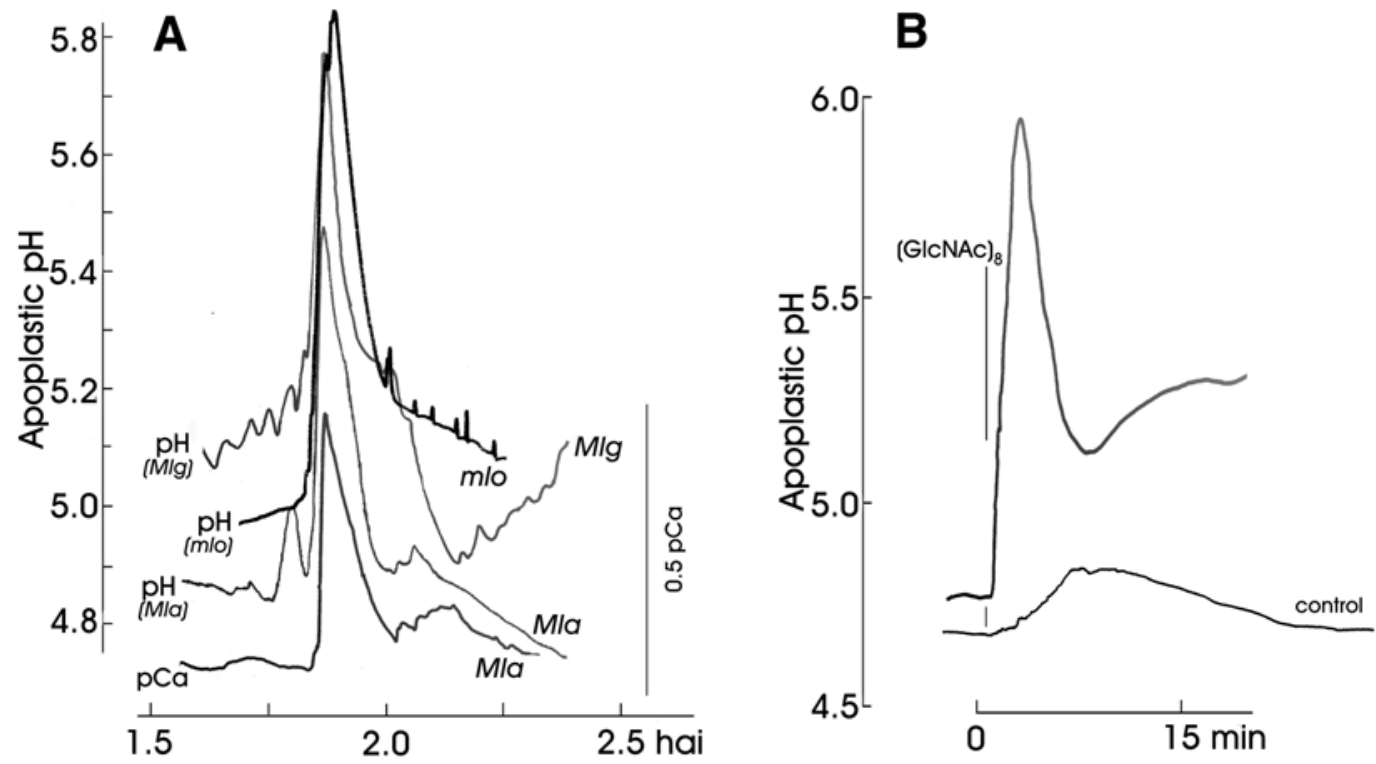

Fig. 2. Transient $\mathrm{pH}$ changes measured in the substomatal apoplast of barley leaves. A, Leaves of the indicated genotypes were inoculated with Blumeria graminis f. sp. hordei A6 conidia. Kinetics are measurements from different leaves. Mean pH changes were $0.82(n=3)$ for I-mlo5; $0.62(n=4)$ for IMla12; and $0.59(n=2)$ for I-Mlg. Also included is a $\mathrm{Ca}^{2+}$ response (pCa) of I-Mla12 (mean $\left.0.44 ; n=3\right)$. For the sake of comparison the kinetics were aligned. B, Apoplastic pH measured in the substomatal cavity of a barley (susceptible Ingrid) leaf after pressure injection of $1 \mu \mathrm{M}$ chitooctaose (GlcNAc) $)_{8}$ into a stoma nearby. Representative of three equivalent tests (mean $\mathrm{pH}$ change, 1.32). Prior to the injection of chitooctaose, the apoplastic space was desensitized by injecting twice the solution without $(\mathrm{GlcNAc})_{8}$. The reaction to the second response is shown as control. hai $=$ hours after inoculation. 
spikes in the case of susceptible Ingrid and as longer lasting transients with I-mlo5 or I-Mlg may have its reason in an interaction with the fungus. It is conceivable that the fungus tries to resist the $\mathrm{pH}$ shift in the alkaline direction by $\mathrm{H}^{+}$pump activation and, thus, causes substantial transient acidification. It is also possible that such shifts are caused by several hyphae originating from different conidia.

\section{The biological implications of the early pH changes.}

As shown in Figures 1 and 2, a first strong $\mathrm{pH}$ response following the inoculation of barley leaves with powdery mildew conidia occurs after about two hours. The transient alkalinization kinetics, which peak within two min, are reminiscent of the $\mathrm{pH}$ transients observed in tomato suspension cultured cells and alfalfa responding to lipochito-oligosaccharides (Felle et al. 1998), chitin fragments (Felix et al. 1993; Felle et al. 2000a), or both. In fact, as Figure 2B clearly shows, injection of $(\mathrm{GlcNAc})_{8}$ directly into the leaf apoplast resulted in a $\mathrm{pH}$ response quite similar that induced by Blumeria graminis. We therefore suggest that the early rapid $\mathrm{pH}$ response is the result of a first encounter of the leaf surface (plasma membrane), possibly with the chitin constituents of the fungal cell wall. Previous data (Okada et al. 2002) as well as our own work (not shown) demonstrate the elicitor activity of chitin oligosaccharides in barley, resulting in reactive oxygen generation and $P R$ gene activation. Since barley chitinases are constitutively present and expressed early in response to Blumeria graminis both in resistant and susceptible plants (Gregersen et al. 1997), one may speculate whether nonspecific plant defense might be involved in the release of chitin elicitors. The close contact of barley and Blumeria graminis f. sp. hordei probably occurred after cutinases from the PGT had given the fungus access to the cell wall and the plasma membrane of the leaf epidermis, which then responded to the chitin fragments with a typical elicitor reaction. Cutin monomers are known to induce resistance in barley to Blumeria graminis (Schweizer et al. 1996) and to condition cucumber plants to express early defense responses such as $\mathrm{H}_{2} \mathrm{O}_{2}$ accumulation in response to the elicitor chitosan (Fauth et al. 1998). Possibly, Blumeria graminis-
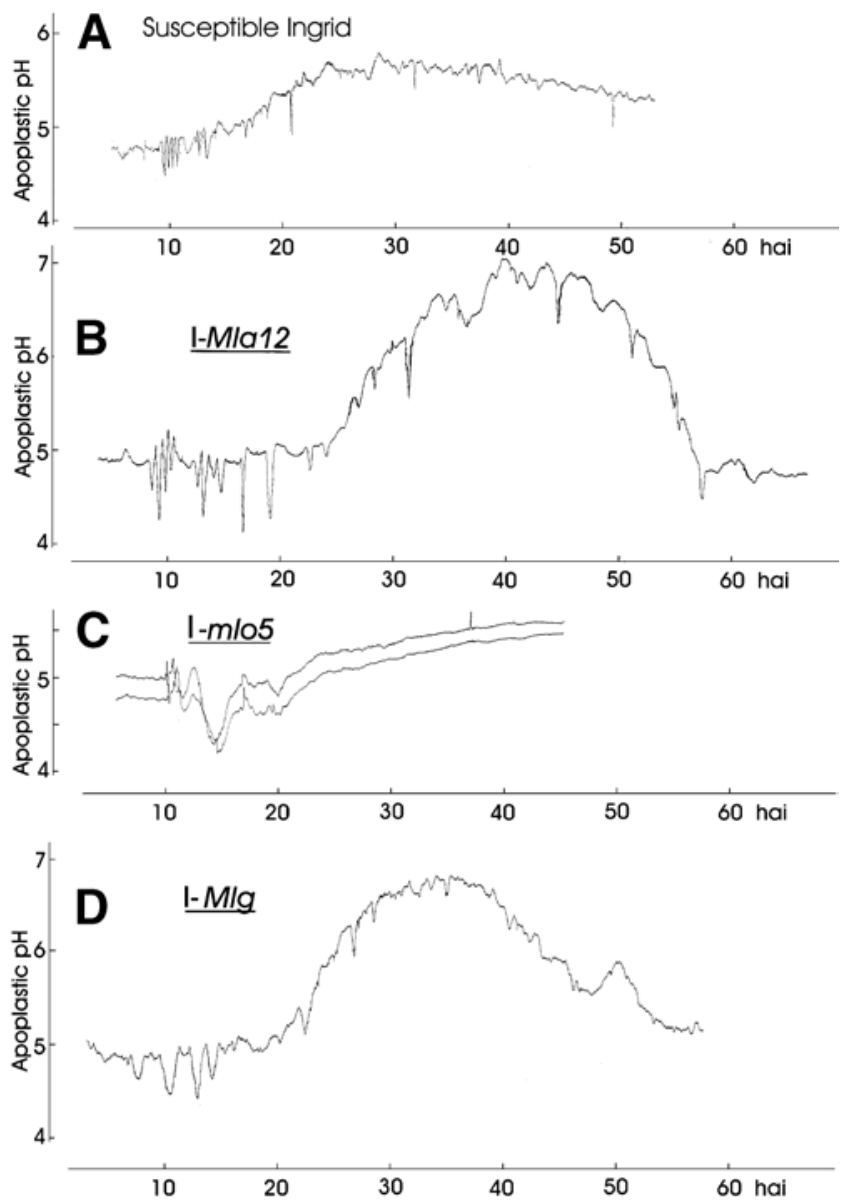

Fig. 4. Comparison of intermediate and long-term apoplastic pH responses of the indicated barley genotypes after inoculation with Blumeria graminis f. sp. hordei A6 conidia. Representative recordings of at least three equivalent measurements each. For I-mlo5, two measurements on the same leaf are shown. hai = hours after inoculation.
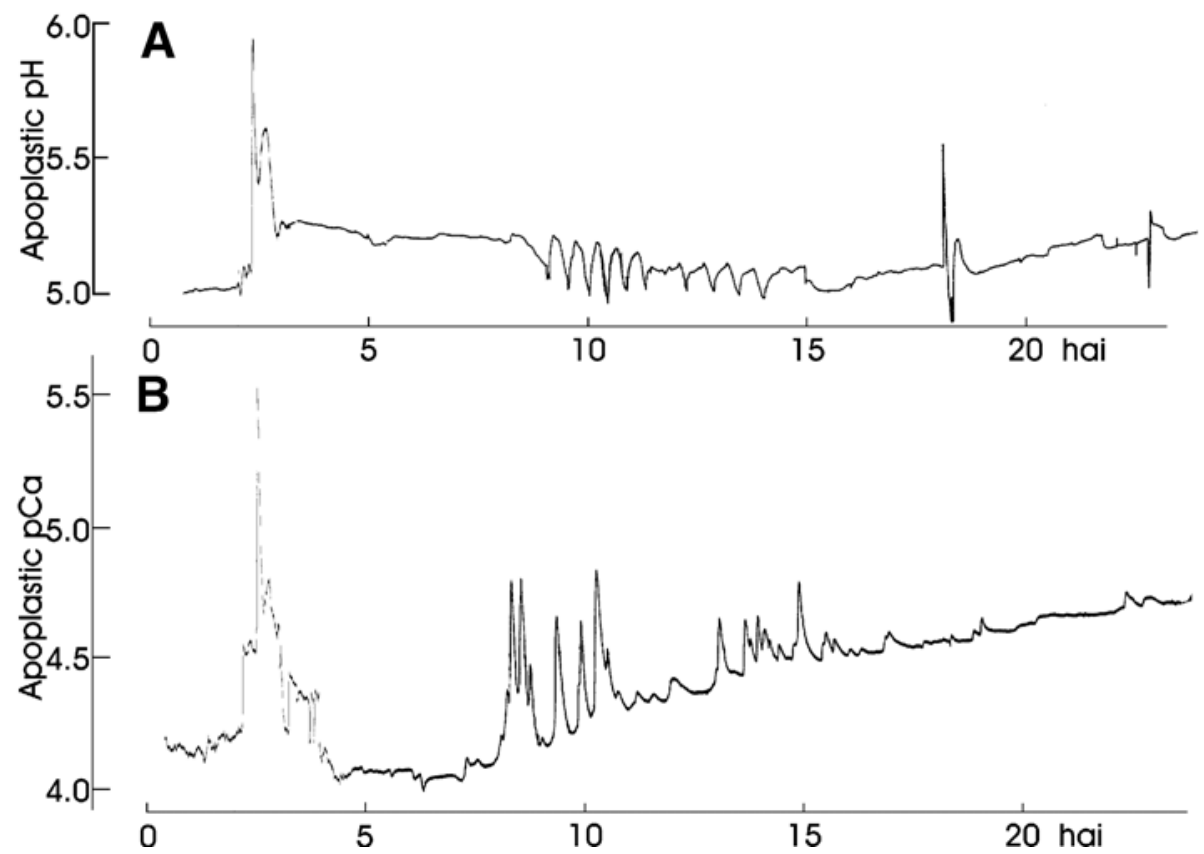

Fig. 3. Short-term and intermediate apoplastic $\mathrm{pH}$ and $\mathrm{Ca}^{2+}$ changes following inoculation of barley leaves (susceptible parent Ingrid) with Blumeria graminis f. sp. hordei A6 conidia. A, Apoplastic pH. B, Apoplastic $\mathrm{Ca}^{2+}(\mathrm{pCa})$. Recordings are from different leaves. Representative of four $(\mathrm{pH})$ and two (pCa) equivalent measurements. hai $=$ hours after inoculation. 
released cutin monomers are perceived early in barley to induce gene expression in a $\mathrm{pH}$ - and $\mathrm{Ca}^{2+}$-independent manner and to prime barley for a second round of responses including ion activity changes when typical elicitors are released. However, since ion fluxes are usually understood as the first plant responses to pathogens, cutin monomers themselves might have triggered apoplastic ion milieu changes. Studies are underway to investigate the transfer of information before 2 hai.

As early alkalinization was observed in all tested near-isogenic genotypes in an $R$ gene-independent manner, this early event is rated "nonspecific." Interestingly, around 2 hai, cytoplasma aggregations can be observed in the attacked cells (Beckhove et al. 1996). We can exclude the hypothesis that the effects were caused by the enzymatic action of plant cell walldegrading enzymes (cellulase and hemicellulase). First, such enzymes cause a different type of apoplastic alkalinization (persistent instead of transient) as demonstrated by Felix and associates (1993) and Carden and Felle (2003). Second, heatdenatured, cell wall-degrading enzymes do not lose their effectiveness (Carden and Felle 2003; Enkerli et al. 1999; FurmannMatarasso et al. 1999).

\section{Implications of the long-term apoplastic $\mathrm{pH}$ changes.}

The slow and persistent long-term $\mathrm{pH}$ changes apparently are alkalinizations that seem to have the general goal to minimize and obstruct fungal growth biochemically. Even with the susceptible line Ingrid, such a $\mathrm{pH}$ increase is observed, albeit not as drastic as that found with I-Mlg and I-Mla12, which much more frequently mount a HR. The intermediate response of Ingrid indicates that we measured, at this timepoint, semisystemic responses. Obviously, the changes in susceptible Ingrid are not sufficient to effectively stop fungal growth. This basic action, however, appears augmented in the HR-mounting lines in which changes are maximal, and apoplastic $\mathrm{pH}$ may increase by over two units to reach values close to cytosolic $\mathrm{pH}$. The observation of the temporal correspondence of HR and $\mathrm{pH}$ increase is striking and may indicate a causality. This is supported by the absence of a $\mathrm{pH}$ increase at 24 hai with Imlo5, a genotype that already arrests fungal growth exclusively through the formation of effective papillae, the formation of which might be signaled by the massive transient acidifications around 8 and 12 hai. Such apoplastic acidification also could be caused by the fungus for its own benefit, a scenario in which acidification could facilitate $\mathrm{H}^{+}$-driven nutrient uptake by Blumeria graminis f. sp. hordei or counteract alkalinization that might also be important for apoplastic defense. The latter has been reported, for instance, in the French bean-Colletotrichum lindemuthianum system (Bolwell et al. 2002). On the other hand, apoplastic alkalinization per se imposes rather unfavorable conditions for the fungus. First, being an obligate biotrophic pathogen, Blumeria graminis must rely on uptake of organic material from living host cells that, according to chemiosmotic principles, has to be transported via $\mathrm{H}^{+}$symport. As this is far more effective in acidic surrounding (apoplastic $\mathrm{pH}$ of barley being below 5) than at neutral $\mathrm{pH}$, transport of organic matter is heavily impaired, causing a retarded growth of the fungus. Second, cell wall-degrading enzymes and the like are shifted away from their $\mathrm{pH}$ optimum, which again makes an infection more and more difficult. Interestingly, the $\mathrm{pH}$ increase in I-mlo5 did not start at 24 hai but simultaneously with the formation of the effective papillae, reaching a maximum well before the time the HR usually started. This makes sense because, due to the fungal growth arrest by the effective papillae, no further $\mathrm{pH}$ increase was necessary. Our results agree with the frequent observation that elicitors always cause external (apoplastic) alkalinization, shifts that can be explained by a deactivation of the plasma membrane $\mathrm{H}^{+}$pump, efflux of organic anions or, as suggested by Dangl and associates (1996), with an influx of $\mathrm{H}^{+}$in exchange for $\mathrm{K}^{+}$. Since the massive alkalinization does not occur before but during HR (Fig. 4), we favor the hypothesis that apoplastic $\mathrm{pH}$ change is not a prerequisite for HR but rather a result thereof, i.e., of an altered, probably disturbed membrane transport or lost membrane integrity.

We demonstrate that the noninvasive microprobe technique produces clear evidence for reconsidering previous hypotheses on apoplastic $\mathrm{pH}$ changes under biotic and abiotic stresses and, for the first time, provides a reliable basis for judgments of host apoplastic enzyme activity changes under pathogen challenge.

\section{MATERIALS AND METHODS}

\section{Plants, pathogens, and inoculation.}

Barley (Hordeum vulgare L.) cv. Ingrid (susceptible parent line) as well as the resistant backcross lines Ingrid-Mlg (I$\mathrm{Mlg}$ ), Ingrid-Mla12 (I-Mla12), and Ingrid-mlo5 (I-mlo5) were grown at $20^{\circ} \mathrm{C}, 50$ to $60 \%$ relative humidity, and a 16 -h photo period $\left(60 \mu \mathrm{mol} \mathrm{m} \mathrm{m}^{-2} \mathrm{~s}^{-1}\right.$ photon flux density). First leaves of 7 to 10-day-old seedlings were inoculated with conidia from Blumeria graminis (DC.) Speer f. sp. hordei EM Marchal, race A6 (Wiberg 1974) and were placed immediately in the measuring cuvette.

\section{Cuvette and apoplastic measurements.}

The technique and setup for measuring apoplastic ion activities in grass leaves have been described recently (Hanstein and Felle 1999). Briefly, the two-chamber cuvette allowed a constant perfusion of one side but left the other side dry. The ground reference electrode was placed in the perfusion part. Access to the leaf apoplast was achieved from the dry chamber (separated from the wet chamber by an insulating plexiglass bar) by inserting the blunt electrodes carefully (without damaging cells) at an angle of approximately $45^{\circ} \mathrm{C}$ through the open stomata into the cavity below. Contact of the electrodes with the apoplastic water film was signaled by the closing of the electrical circuit. In cases when displacement of the electrode tips did occur, the electrodes were either repositioned or the measurement was terminated. Since the electrical resistance from the ion-selective electrodes through the apoplast network to the grounded bath reference was high (1 to $20 \mathrm{M} \Omega$, depending on the distance from the veins), a blunt leaf voltage reference microelectrode was inserted through a neighboring stoma and continuously recorded the apoplastic voltage. The difference between the signals of these electrodes was recorded as the net trace. When appropriate and interesting to the argument, the voltage trace was recorded, also. This approach guaranteed that unphysiological voltage changes picked up by the two electrodes were filtered out. The bath was covered with parafilm to prevent it from drying, leaving only a small opening for the bath ground reference. With this arrangement, continuous measurements for three to four days could be carried out. The formation of fungal germ tubes and appressoria from time to time was controlled microscopically. To guarantee a humid atmosphere for proper germination, a chamber partly filled with a moist sponge, was put over the dry part of the leaf. The upper part of this chamber (cover) had a $3 \times 15-\mathrm{mm}$ slit to permit the approach of the electrodes.

Microinjections of chitin fragments were carried out by pressure through a custom-built device. The injection needle was filled with $1 \mu \mathrm{M}$ chitooctaose dissolved in a medium adjusted to $\mathrm{pH} 4.8,5 \mathrm{mM} \mathrm{K}^{+}$, and $0.1 \mathrm{mM} \mathrm{Ca}^{2+}$, conditions that closely resembled the apoplastic fluid. Under microscopic control, the injection needle was carefully inserted into the substomatal cavity of an open stoma, and the injectate was released into the 
leaf apoplast through pressure. The response to this treatment was monitored in a stoma nearby.

\section{Ion-selective microelectrodes.}

The electrical setup for the fabrication and application of ion-selective microelectrodes and their extracellular application in leaves has been described previously (Felle et al. 2000a; Hanstein and Felle 1999).The tips of the electrodes were about $2 \mu \mathrm{m}$ in diameter, blunt, and heat-polished. Single pipettes were pulled on a two-stage patch-clamp puller (List Instr., Darmstadt, Germany) and silanized internally, using a $0.2 \%$ tributylsilane/chloroform solution. After heat-stabilization at $200^{\circ} \mathrm{C}$ for $1 \mathrm{~h}$, the cool pipettes were back-filled with the respective sensor cocktail. To give the sensor enough firmness to stay in place, the cocktails (Fluka $95297 \mathrm{H}^{+} 21196 \mathrm{Ca}^{2+}$; Fluka Chemical Corp. Milwaukee, WI, U.S.A.) were dissolved in a mixture of polyvinylchloride and tetrahydrofuran $\left(40 \mathrm{mg} \mathrm{ml}^{-1}\right)$ at a ratio of $70: 30(\mathrm{vol} / \mathrm{vol})$. After evaporation of the tetrahydrofuran, the remaining firm gel was topped up with the undiluted sensor cocktail, followed by the reference solution, which consisted of $100 \mathrm{mM} \mathrm{Mes} /$ Tris mixed to $\mathrm{pH} 6$ in $0.5 \mathrm{M} \mathrm{KCl}$. After equilibration, these electrodes gave stable responses for several weeks when stored in a dry chamber. The electrodes were connected to a high-impedance amplifier (FD 223; WPInstruments, Sarasota, FL, U.S.A.) that simultaneously measured and subtracted the signals coming from the ion-selective electrode and the voltage reference electrode, to obtain the net kinetics of the free ion concentration under investigation. The signals were recorded on a chart recorder (L 2200, Linseis, Selb, Germany).

\section{ACKNOWLEDGMENTS}

This work was supported by the Deutsche Forschungsgemeinschaft (Fe 213/14-1; FOR 343/2).

\section{LITERATURE CITED}

Bayles, C., and Aist, J. R. 1987. Apparent calcium mediation of resistance of an mlo barley mutant to powdery mildew. Physiol. Mol. Plant Pathol. 30:337-345.

Beckhove, U., Kogel, K.-H., and Schmelzer, E. 1996. Acquired resistance in barley: Early accumulation of the potentiometric dye DIOC6 in cytoplasmic aggregations beneath the primary germ tube of Erysiphe graminis f. sp. hordei of cells of barley coleoptiles induced by 2,6dichloroisonicotinic acid. Pages 475-481 in: Modern Fungicides and Antifungal Compounds. 11th International Symposium 1995. H. Lyr, P. E. Russell, H. D. Sisler, eds. Intercept, Andover, MA, U.S.A.

Blume, B., Nürnberger, T., Nass, N., and Scheel, D. 2000. Receptormediated increase in cytoplasmic free calcium required for activation of pathogen defence in parsley. Plant Cell 12:1425-1440.

Bolwell, G. P., Bindschedler, L. V., Blee, K. A., Butt, V. S., Davies, D. R., Gardner, S. L., Gerrish, C., and Minibayeva, F. 2002. The apoplastic oxidative burst in response to biotic stress in plants: A three-component system. J. Exp. Bot. 53:1367-1376.

Carden, D. E., and Felle, H. H. 2003. The mode of action of cell walldegrading enzymes and their interference with Nod factor signaling in Medicago sativa root hairs. Planta 216:993-1002.
Dangl, J. L., Dietrich, R. A., and Richberg, M. H. 1996. Death don't have no mercy: Cell death programs in plant microbe interactions. Plant Cell 8:1793-1807.

Enkerli, J., Felix, G., and Boller, T. 1999. The enzymatic activity of fungal xylanase is not necessary for its elicitor activity. Plant Physiol. 121:391-397.

Fauth, M., Schweizer, P., Buchala, A., Markstadter, C., Riederer, M., Kato, T., and Kauss, H. 1998. Cutin monomers and surface wax constituents elicit $\mathrm{H}_{2} \mathrm{O}_{2}$ in conditioned cucumber hypocotyls segments and enhance the activity of other $\mathrm{H}_{2} \mathrm{O}_{2}$ elicitors. Plant Physiol. 117:1373-1380.

Felix, G., Regenass, M., and Boller, T. 1993. Specific perception of subnanomolar concentrations of chitin fragments by tomato cells: Induction of extracellular alkalinization, changes in protein phosphorylation, and establishment of a refractory state. Plant J. 4:307316.

Felle, H. H., and Hanstein, S. 2002. The apoplastic pH of the substomatal cavity of Vicia faba leaves and its regulation responding to different stress factors. J. Exp. Bot. 53:73-82.

Felle, H. H., Kondorosi, É., Kondorosi, Á., and Schultze, M. 1998 The role of ion fluxes in Nod factor signaling in Medicago sativa. Plant $\mathrm{J}$. 13:455-463.

Felle, H. H., Kondorosi, É., Kondorosi, Á., and Schultze, M. 2000a. How alfalfa root hairs discriminate between Nod factors and oligochitin elicitors. Plant Physiol. 124:1373-1380.

Felix, G., Grosskopf, D. G., Regenass, M., and Boller, T. 1991. Rapid changes of protein phosphorylation are involved in transduction of the elicitor signal in plant cells. Proc. Natl. Acad. Sci. U.S.A. 88:88318834.

Furmann-Matarasso, N., Cohen, E., Du, Q., Chejanovsky, N., Hanania, U., and Avni, A. 1999. A point mutation in the ethylene-inducing xylanase elicitor inhibits the $\beta$-1-4-endoxylanase activity but not the elicitation activity. Plant Physiol. 121:345-351.

Gregersen, P. L., Thordal-Christensen, H., Főrster, H., and Collinge, D. B. 1997. Differential gene transcript accumulation in barley leaf epidermis and mesophyll in response to attack by Blumeria graminis f. sp. hordei. Phys. Mol. Plant Pathol. 51:85-97.

Hanstein, S., and Felle, H. H. 1999. The influence of atmospheric $\mathrm{NH}_{3}$ on the apoplastic $\mathrm{pH}$ of green leaves: A non-invasive approach with $\mathrm{pH}$ sensitive microelectrodes New Phytol. 143:333-338.

Hückelhoven, R., Fodor, J., Preis, C., and Kogel, K.-H. 1999. Hypersensitive cell death and papilla formation in barley attacked by the powdery mildew fungus are associated with $\mathrm{H}_{2} \mathrm{O}_{2}$ but not with salicylic acid accumulation. Plant Physiol. 119:1251-1260.

Jørgensen, J. H. 1994. Genetics of powdery mildew resistance in barley. Crit. Rev. Plant Sci. 13:97-119.

Kim, M. C., Panstruga, R., Elliott, C., Muller, J., Devoto, A., Yoon, H. W., Park, H. C., Cho, M. J., and Schulze-Lefert, P. 2002. Calmodulin interacts with MLO protein to regulate defence against mildew in barley. Nature 416:447-451.

Mithöfer, A., Ebel, J., Bhagwat, A. A., Boller, T., and Neuhaus-Url, G. 1999. Transgenic aequorin monitors cytosolic calcium transients in soybean cells challenged with $\beta$-glucan or chitin elicitors. Planta 207:566-574.

Okada, M., Matsumura, M., Ito, Y., and Shibuya, N. 2002. High-affinity binding proteins for $N$-acetylchitooligosaccharide elicitor in the plasma membranes from wheat, barley and carrot cells: Conserved presence and correlation with the responsiveness to the elicitor. Plant Cell Physiol. 43:505-512.

Schweizer, P., Jeanguenat, A., Whitagre, D., Métraux, J.-P., and Mösinger, E. 1996. Induction of resistance in barley against Erysiphe graminis f. sp. hordei by free cutin monomers. Physiol. Mol. Plant Pathol. 49:103120.

Wiberg, A. 1974. Genetical studies of spontaneous sources of resistance to powdery mildew in barley. Hereditas 77:89-148. 